\title{
CARACTERÍSTICAS PETROQUÍMICAS E GEOCRONOLÓGICAS DO GRANITO MANDACARU (PI)
}

\author{
CLÓVIS VAZ PARENTE*, REINHARDT A. FUCK **, \\ MOACIR J. BUENANO MACAMBIRA*** E ARIEL PROVOST***
}

\begin{abstract}
The post-tectonic A-type Mandacaru Granite intruded the molasse sequence of the Catolé Formation, as well as epimetametamorphic metassediments and granite-gneiss terrane of the Brasiliano Cycle Jaguaribeano Belt. The granitic rocks crystallized from a $\mathrm{H}_{2} \mathrm{O}$-poor subalkaline to slightly alkaline magma, probably derived from lower crustal material. $\mathrm{Rb}-\mathrm{Sr}$ isotope determinations yielded an age of $559 \pm 8 \mathrm{Ma}, \mathrm{Ri}=0.70924 \pm 0.00010$.
\end{abstract}

INTRODUÇÃO O Granito Mandacaru corresponde a um corpo pós-tectônico intrusivo em uma sequiência molassóide do Eopaleozóico (Formação Catolé) e em rochas granito-gnáissicas e epimetamorfitos (Sequência São Julião) atribuídos ao Proterozóico Superior. Os estudos anteriores ao de Parente (1984) indicavam que esta intrusão corresponderia a um porphyry copper (Farina 1980, Terazu 1980, 1981, Gaall 1982, Lopes Filho et al. 1982), e que representava um complexo de intrusões múltiplas (Lopes Filho et al. 1982).

No presente trabalho são apresentadas as feições geo* químicas e geocronológicas mais importantes do Granito Mandacaru. A geologia e petrografia do granito são discutidas em detalhe em outro trabalho (Parente \& Fuck, no prelo) e não serão pormenorizadas aqui.

O Granito Mandacaru localiza-se na região homônima, no município de São Julião, no leste do Estado do Piauí, próximo à divisa com o Ceará. $\mathrm{O}$ acesso é realizado por via terrestre, pelas rodovias BR-316 e BR-230. Geologicamente, está inserido na porção sudoeste da Faixa de Dobramentos Jaguaribeana, na borda leste da Bacia do Parnaíba (Fig. 1).
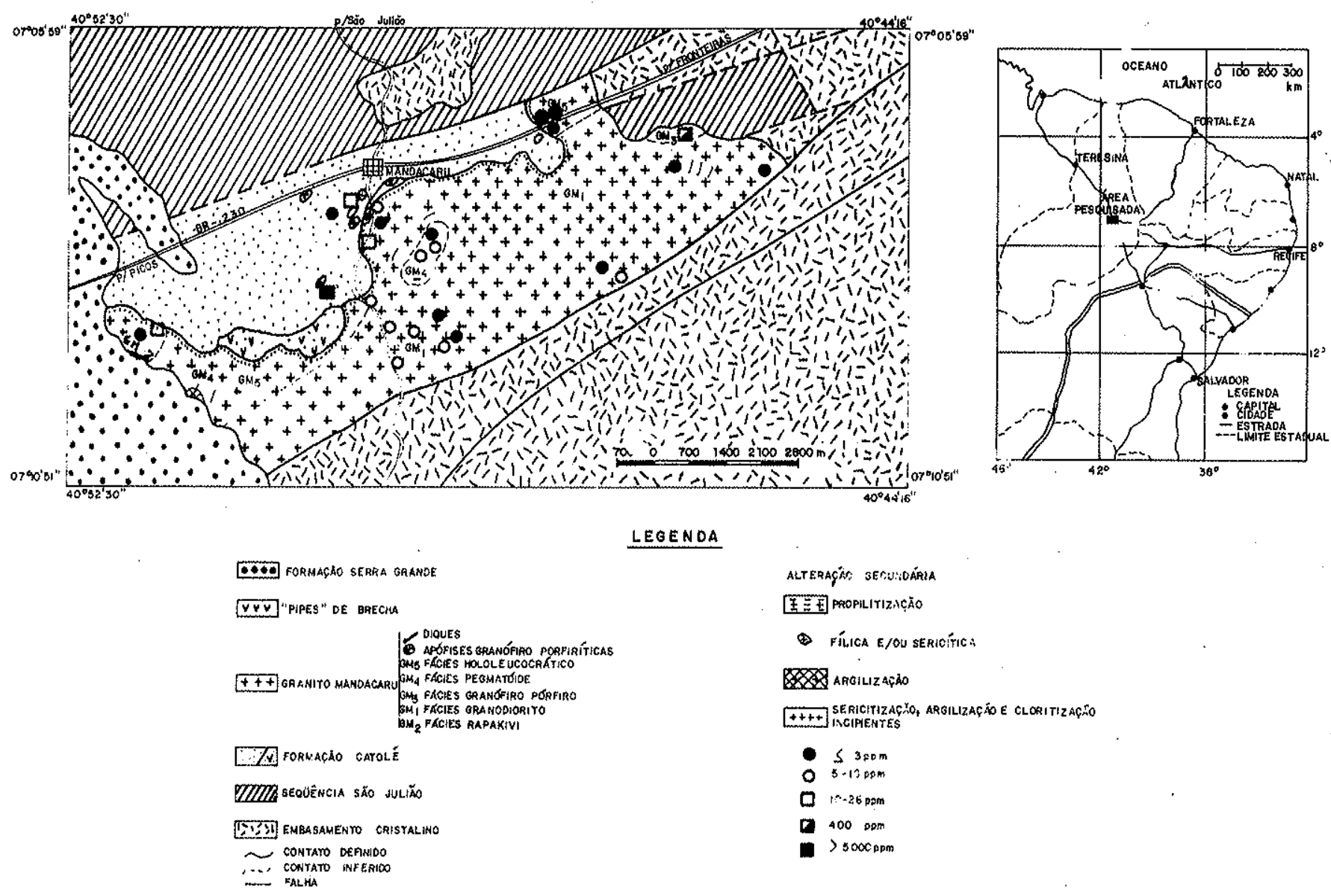

LEOENDA

$$
\begin{aligned}
& \text { ALTERAG̈OS SETHUDÁRIA }
\end{aligned}
$$

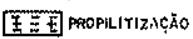

$$
\begin{aligned}
& \text { - Fíllca e/OU SERicífica } \\
& \text { AFGILZZ AÇAOAO } \\
& \text { St++t INCIPIENYES } \\
& \text { - } S_{5 \rightarrow 12 \mathrm{pgmm}}^{3 \mathrm{FDm}} \\
& \text { (1) } 1226 \mathrm{psm} \\
& \text { D. } 400 \text { pom } \\
& \text { m. }>5000 \mathrm{ppm}
\end{aligned}
$$

Figura 1-Mapa geológico e distribuição geoquimica do Cu nas rochas do Granito Mandacaru

\footnotetext{
* Departamento de Geologia, Universidade Federal do Ceará. CEP 60000, Fortaleza, CE ** Departamento de Geociências, Universidade de Brasília. CEP 70910, Brasília, DF

:r** Centro de Geociências, Universidade Federal do Pará. CEP 66000, Belém, PA
} 
CARACTERÍSTICAS GEOLOGICAS DO GRANITO MANDACARU O Granito Mandacaru possui forma irregular alongada, com cerca de $12 \mathrm{~km}$ de diâmetro maior, alinhado na direção NE-SW. É basicamente controlado por sistema de falhas de direção NE-SW, que o coloca a sul em contato com as rochas granito-gnáissicas e a norte com os epimetamorfitos (filitos, metarcóseos, quartzitos e calcários marmorizados) da Sequêência São Julião e as rochas vulcânicas (basalto andesítico, dacito, riólitos e piroclásticas) e sedimentares (ruditos argilosos, grauvaca arcoseana, arenito arcoseano e siltitos) da Formação Catolé, das quais contém encraves. A oeste é recoberto pelas rochas sedimentares da Formação Serra Grande. De relevo pouco acentuado, apresenta uma passagem geomorfologica quase imperceptível para os terrenos ocupados pela Seqüência São Julião, pela Formação Catolé e pelas rochas granito-gnáissicas pré-cambrianas.

Em função da textura e/ou composição mineralógica, cinco fácies petrográficas podem ser distinguidas no Granito Mandacaru: fácies granodiorito, fácies pegmatítica, fácies granófiro pórfiro, fácies granito hololeucocrático e fácies rapakivi (Fig. 1).

0 contato entre a maioria desses fácies é transicional, embora não seja observado em todos eles, de modo que é difícil estabelecer com segurança se é abrupto ou gradacional como um todo. Vale assinalar que não foram encontrados xenólitos e/ou autólitos que pudessem indicar um mecanismo de intrusões múltiplas. Dessa forma, as diferenças faciológicas são atribuídas a estágios distintos de cristalização e resfriamento do corpo durante a ascensão do magma granítico.

As rochas graníticas apresentam, como um todo, granulação média a grossa, aspecto maciço e são normalmente isotrópicas. Em geral, são leucocráticas, os minerais ferromagnesianos, representados por hornblenda e subordinadamente biotita, constituindo menos de $10 \%$ do volume da rocha. Diques e apófises de dimensóes reduzidas de microgranito, microdiorito, basalto andesítico e raramente pegmatito cortam tanto os diferentes tipos faciológi$\cos$ da intrusão quanto a Formação Catolé, sendo especialmente frequientes ao longo da borda oeste do granito, onde constituem um verdadeiro colar de apófises de direção NE-SW. Entre esses destacam-se principalmente os granófiros, os tipos mais comuns, especialmente nas apófises.

0 contato do granito com as encaixantes, em particular com as rochas da Formação Catolé, é, caracterizado por uma auréola termometamórfica pouco pronunciada, que contém minerais de baixa temperatura representados por quartzo-muscovita-clorita-albita-epídoto nas rochas sedimentares e clorita-epídoto-carbonato-albita-uralita-biotita nas rochas vulcânicas, paragêneses que correspondem ao fácies albita-epídoto hornfels (Turner 1981).

Por outro lado, a associação comum das rochas graníticas com granófiros e rílitos e o baixo teor de minerais hidratados, sobretudo biotita e hornblenda (muscovita é ausente), indicam que o líquido granítico migrou quase até a superfície sem cruzar o solidus, posicionando-se em condições de $\mathrm{T}$ acima de $800^{\circ} \mathrm{C}$ e profundidade em torno de 3 $\mathrm{km}$. Nestas condiçōes, poder-se-ia esperar uma auréola termometamórfica pronunciada devido ao próprio contraste térmico do magma granítico com as rochas encaixantes. No entanto, a natureza e o ambiente das encaixantes (rochas psamopsefíticas dominantes, fraturadas e formadas em ambiente com tendência redutora) sugerem que a solidificação do Granito Mandacaru foi acompanhada de resfriamento por conveç̧ão de fluidos originados das encaixantes. Esse fato inibiu em grande parte a transferência de calor do granito para suas encaixantes bem como alterou e modificou sua associação mineral, o que explica a maior presença de alteração secundária nas zonas de borda.

CARACTERISTICAS GEOQUÍMICAS Vinte e sete amostras dos tipos petrográficos maịs representativos foram analisadas quimicamente nos laboratórios da Geologia e Sondagens Ltda. (Geosol) em Belo Horizonte e da Universidade de Brasília.

As análises dos elementos maiores foram obtidas por métodos instrumentais combinados de fluorescência de raios $\mathrm{X}$, absorção atômica e volumetria realizados nos laboratórios da Geosol e da Universidade de Brasília, enquanto as dos elementos-traços foram realizadas por espectrografia de emissão de 30 elementos nos laboratórios da Geosol.

Os resultados das análises com as respectivas composiçzes normativas são apresentados na tabela 1 . Na seleção das amostras foi levada em consideração sua distribuição no interior da intrusão, procurando-se sempre analisar as amostras menos alteradas.

As rochas do Granito Mandacaru são caracterizadas por um alto teor de $\mathrm{SiO}_{2}(>72 \%), \mathrm{K}_{2} \mathrm{O} \cong 5 \%, \mathrm{Na}_{2} \mathrm{O} \cong 3,5 \%$, baixo teor de $\mathrm{CaO}$ e $\mathrm{MgO}(<1 \%)$, razão $\mathrm{Al}_{2} \mathrm{O}_{3} / \mathrm{Na}_{2} \mathrm{O}$ + $\mathrm{K}_{2} \mathrm{O}+\mathrm{CaO}>1$ e coríndon normativo quase sempre ausente ou com valores $<1$, apesar de duas amostras apresentarem valores acima de 2. A razão $\mathrm{Fe}_{2} \mathrm{O}_{3} / \mathrm{FeO}$ varia de amostra para amostra, o que indica provável interação de água meteórica ou das encaixantes nos estágios finais de cristalização. São rochas alcalinas e subalcalinas, de afinidade sobretudo potássica. Isso é mais bem observado no diagrama de variação de alcalinidade $x$ silica (Wright 1969), reproduzido na figura 2 , em que a quase totalidade das amostras do Granito Mandacaru está plotada no campo alcalino, com afinidade aos campos alcalino intermediário e fortemente alcalino. No diagrama de variação $\mathrm{CaO}-\mathrm{Na}_{2} \mathrm{O}$ $-\mathrm{K}_{2} \mathrm{O}$ (Fig. 3), que acentua a distribuição dos álcalis, observa-se nos termos mais diferenciados, principalmente nas rochas de diques e apófises, um enriquecimento de $\mathrm{K}_{2} \mathrm{O}$ em relação a $\mathrm{CaO}$ e $\mathrm{Na}_{2} \mathrm{O}$, o que caracteriza sua afinidade potássica. $\mathrm{O}$ baixo teor de $\mathrm{CaO}$ e a composição dos plagioclásios dominantemente albíticos $\left(\mathrm{An}_{3-9}\right)$ permitem classificar - Granito Mandacaru, ainda, como um granito subsolvus, considerando a presença de feldspato potássico e plagioclásio na rocha (Tutle \& Bowen 1958). A alta razão $\mathrm{Al}_{2} \mathrm{O}_{3} / \mathrm{Na}_{2} \mathrm{O}+\mathrm{K}_{2} \mathrm{O}+\mathrm{CaO}$ encontrada e a eventual presença de coríndon normativo, sugerindo um caráter pera. luminoso, devem-se à relativa imobilidade de $\mathrm{Al}_{2} \mathrm{O}_{3}$ em relação a $\mathrm{Na}_{2} \mathrm{O}, \mathrm{K}_{2} \mathrm{O}$ e CaO nos processos de altẹação ou mesmo no baixo teor de $\mathrm{CaO}$, que é comum a essas rochas. Essa assertiva encontra suporte na ausência de minerais típicos dos granitos peraluminosos, tais como muscovita, topázio, turmalina, granada, cordierita e silimanita (Clarke 1981), e na presença de acmita normativa, em algumas amostras, sobretudo nas menos alteradas, $o$ que indica que as rochas são pobres em $\mathrm{Al}_{2} \mathrm{O}_{3}$.

A razão $\mathrm{K} / \mathrm{Rb}$ varia de 215 nas rochas do fácies granodiorito a 88 nas rochas do fácies granito hololeucocrático. De acordo com Hanson (1978), a razão K/Rb diminui em direção às rochas mais ạ́cidas em uma suíte consangüínea, o que permite dizer que os granitos hololeucocráticos re- 
Tabela $1 A$ - Análises químicas dos elementos maiorais (\%) e elementos menores (ppm) do Granito Mandacaru

\begin{tabular}{|c|c|c|c|c|c|c|c|c|c|c|c|c|c|c|c|c|c|c|c|c|c|c|c|c|c|}
\hline $\begin{array}{c}\text { AMOSTRA } \\
\text { DE } \\
\text { ROCHAS }\end{array}$ & $\mathrm{SiO}_{2}$ & ${ }_{2} \mathrm{O}_{3}$ & $\mathrm{Fe}_{2} \mathrm{O}_{3}$ & Feo & $\mathrm{CaO}$ & $\mathrm{MgO}$ & $\mathrm{Na}_{2} \mathrm{O}$ & $\mathrm{K}_{2} \mathrm{O}$ & $\mathrm{MnO}$ & $\mathrm{P}_{2} \mathrm{O}_{\mathrm{s}}$ & $\mathrm{TiO}_{2}$ & P.P. & $\mathbf{F}$ & Sṇ & $\mathrm{Nb}$ & $\mathbf{Y}$ & Mo & $\mathrm{Cu}$ & Be & Ga & 4 & $z_{s}$ & $\mathbf{R b}$ & Sr & $\mathrm{Ba}$ \\
\hline $\mathrm{cv}-0$ & & & to & & & & & & & 0,04 & & 0,58 & $<30$ & $<5$ & & $<10$ & $\leq 5$ & & $<2$ & 15 & $<50$ & 130 & 210 & & \\
\hline & & & & & & & & & & & & & & & & & & & & 16 & & & & & \\
\hline & & & & & & & & & & 0,18 & & 68 & $<0$ & & $<20$ & $\begin{array}{l}100 \\
20\end{array}$ & $5_{5}^{5}$ & $\begin{array}{r}6 \\
26\end{array}$ & $<2$ & 16 & $<-1$ & $\begin{array}{r}94 \\
280\end{array}$ & . & $\begin{array}{l}97 \\
480\end{array}$ & $\begin{array}{r}350 \\
1.850\end{array}$ \\
\hline & & & & & & 0,98 & & & & 0,11 & & $\begin{array}{l}1,00 \\
1,38\end{array}$ & & & & 15 & 5 & 6.160 & & & - & 00 & & & $\begin{array}{l}1.850 \\
1.010\end{array}$ \\
\hline & & & & & & & & & & - & & & $<30$ & $<5$ & & 18 & & & $<2$ & 19 & $<50$ & 27 & & 48 & \\
\hline & & & & & & 0,05 & & & & 0,05 & & & - & 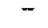 & & & & & - & - & - & 23 & & & \\
\hline & & & & & & 1. & & & & & & & $=$ & $\overline{-}$ & $<$ & & & & - & - & - & 68 & 0 & & \\
\hline & & & & & & 1,0 & & & & & & & $\overline{63}$ & $\overline{<5}$ & $\begin{array}{l}20 \\
12\end{array}$ & & & & $<2$ & $\overrightarrow{17}$ & $<50$ & $\begin{array}{l}84 \\
54\end{array}$ & & & \\
\hline & & & & & & 0,73 & & & & & & & 550 & $<5$ & 24 & & & 5600 & $<2$ & 17 & $<50$ & 190 & & & \\
\hline & & & & & & & & & & & & & & $<$ & 4 & $<$ & & & 2 & 20 & $<50$ & & & & \\
\hline & & & & & & & & & & & & & & & & & & & $s$ & 20 & & & & & \\
\hline & & & & & & & & & & & & & & & & & & & 6 & 19 & & & & & \\
\hline & & & & & & & & & & & & & & & $<20$ & & & & 7 & 18 & 50 & & & & \\
\hline & & & & & & & & & & & & & & & & & & & 4 & 21 & & & & & \\
\hline & & & & & & & & & & & & & & & 1 & & & & 5 & 19 & & & & & \\
\hline & & & & & & & & & & & & & & & & & & & $?$ & & & & & & \\
\hline & & & & & & $0_{n}$ & & & & & & & 17 & & 17 & & & & 5 & & & & & & \\
\hline & & & & & & & & & & & & & & & & & & $<$ & 2 & 9 & & & & 0 & \\
\hline & & & & & & & & & & & & & $\int_{<30}^{114}$ & $<5$ & & & & & 2 & 10 & $<50$ & & & & $\begin{array}{l}1.000 \\
380\end{array}$ \\
\hline & & & & & & & & & & & & & $<30$ & - & & 16 & & $\begin{array}{r}5 \\
10\end{array}$ & 2 & 19 & $<50$ & $\begin{array}{l}92 \\
65\end{array}$ & & & $\begin{array}{l}380 \\
200\end{array}$ \\
\hline & & & & & & & & & & & & & - & - & $<20$ & $<5$ & & 6 & - & - & $=$ & & & & \\
\hline & & & & & 0 & 0, & & & & & & & - & - & 26 & .20 & & & - & - & - & & & 8 & 130 \\
\hline & & & & & & & & & & & & & & & & & & & & & & & & & 2050 \\
\hline & & & & & 0,36 & & & 5,32 & 0,02 & & & & & & & & & & & & & & & & \\
\hline
\end{tabular}

Tabela $1 B$ - Norma CIPW das rochas do Granito Mandacaru

\begin{tabular}{|c|c|c|c|c|c|c|c|c|c|c|c|c|c|c|c|}
\hline AMOSTRA DE ROCHAS & Q & $O_{x}$ & $A b$ & An & Di & Hy & c & Mt & Ap & $\mathbf{z}$ & n & $\mathbf{F i}$ & $\mathbf{H m}$ & Mo & Ac \\
\hline CV-06A & 40,21 & 22,63 & 31,05 & 0,86 & - & $.0,35$ & 2,20 & 1,01 & 0,09 & & 0,08 & - & - & - & - \\
\hline CV-06B & 39,16 & 33,05 & 25,88 & 0,62 & - & 0,26 & 0,15 & 0,55 & $\ldots$ & 0,01 & 0,19 & 0,12 & - & - & - \\
\hline CV-18A & 41,01 & 27,57 & 28,56 & 0,65 & - & 0,38 & 0,53 & 0,40 & - & 0,01 & 0,27 & - & 0,63 & ـ & \\
\hline CV.18B & 9,03 & 34,55 & 35,60 & 8,33 & - & 4,66 & 0,89 & 4,55 & 0,43 & 0,06 & 1,06 & - & & - & - \\
\hline$C V-1 B C$ & 23,66 & 33,55 & 33,43 & 0,49 & - & 2,48 & 1,19 & 2,22 & 0,26 & 0,05 & 0,73 & - & 1,01 & - & - \\
\hline $\mathrm{CV}-18 \mathrm{~F}$ & 36,59 & 45,67 & 15,77 & 0,69 & - & 0,29 & 0,56 & 0,24 & - & - & 0,19 & - & - & - & - \\
\hline CV-20D & 25,09 & 29,87 & 41,17 & 1,94 & 0,27 & & - & 0,19 & 0,12 & - & 0,19 & - & 0,43 & 0,19 & - \\
\hline CV-21D & 21,11 & 35,22 & 35,35 & 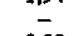 & 3,35 & 1,43 & $\ldots$ & 1,00 & 0,40 & 0,01 & 0,32 & - & - & - & 1,19 \\
\hline CV-26A & 19,35 & 28,91 & 40,88 & 2,88 & $=$ & 2,95 & 1,07 & 1,05 & 0,48 & 0,02 & 0,67 & $\overrightarrow{-}$ & - & & 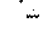 \\
\hline CV-26B & 17,73 & 32,21 & 46,72 & 0,15 & 1,54 & & 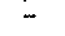 & 0,78 & 0,10 & 0,02 & 0,19 & 0,01 & - & 0,56 & - \\
\hline CV $40 \mathrm{~A}$ & 27,03 & 29,24 & 35,77 & 0,74 & 3,74 & 1,63 & 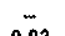 & 0,86 & 0,07 & 0,03 & 0,78 & 0.10 & - & - & - \\
\hline$C V .4 B A$ & 28,77 & 23,95 & 34,26 & 6,82 & - & 2,42 & 0,83 & 1,97 & 0,24 & 0,03 & 0,59 & 0,09 & $\approx$ & - & - \\
\hline CV.50 & 14,35 & 32,78 & 38,54 & 3,22 & 6,04 & 0,75 & 10 & 2,23 & 0,12 & 0.03 & 1,16 & 0,12 & 0,66 & - & - \\
\hline CV.58A & 28,09 & 24,93 & 39,97 & 3,69 & 0 & 1,15 & $1 ; 28$ & 0,59 & 0,07 & 0,02 & 0,19 & 0,02 & - & - & 159 \\
\hline $\mathrm{CV}-69 \mathrm{C}$ & 26,95 & 23,02 & 43,40 & - & 3,22 & 0,95 & - & 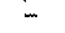 & 0,19 & 0,02 & 0,19 & 0,05 & - & - & 1,59 \\
\hline CV.70A & 24,35 & 30,90 & 38,19 & 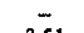 & 4,80 & 0,12 & $\bar{n}$ & - & 0,10 & 0,02 & 0,65 & 0,03 & - & - & 0,47 \\
\hline CV-86A & 25,59 & $\begin{array}{r}25,59 \\
27,6\end{array}$ & 38,08 & 3,51 & $\therefore$ & 1,61 & 2,23 & 0,57 & 0,16 & - & 0,21 & $\overrightarrow{0}$ & $=$ & - & - \\
\hline CV-90A & 22,55 & 27,16 & 41,72 & 0,39 & 4,95 & 0,99 & - & 1,72 & 0,26 & 0,02 & 0,1 & 0,04 & - & - & - \\
\hline CV-104A & 26,29 & 24,34 & 42,99 & 2,53 & 1,35 & 1,01 & $\overline{75}$ & 0,90 & 0,05 & 0,02 & 0,8 & 0,04 & - & - & $=$ \\
\hline CV-139A & 26,68 & $\begin{array}{l}36,92 \\
3310\end{array}$ & $\begin{array}{l}31,06 \\
31,7\end{array}$ & 0,67 & - & 0,99 & 1,25 & 1,67 & 0,1 & 0,05 & 0,5 & 0,03 & $\stackrel{m}{117}$ & $=$ & $=$ \\
\hline & 31,25 & 33,19 & 31,37 & 0,88 & - & 0,13 & 1,12 & 0,0 & 0,0 & 0,03 & 0 & 0,02 & 1,17 & - & - \\
\hline CV-213i & 37, & 23,64 & 29,62 & 5,01 & 0 & 0,51 & 0,57 & 0,7 & 0,1 & $\because$ & 0,1 & - & & - & 04 \\
\hline MA-0 & 28,67 & 34,07 & 34,95 & - & 0,26 & 0,08 & - & 1,10 & 0,1 & 0,01 & 0,1 & - & 0,09 & - & 0,45 \\
\hline MA-1 & & $\begin{array}{l}33,83 \\
3055\end{array}$ & 40,91 & 0,58 & 1,66 & 0,56 & - & 0,71 & 0,2 & 0,02 & 0, & - & 0,83 & - & $\overline{0.88}$ \\
\hline MAA-A & 31,94 & 30,5 & 34,35 & - & 0,45 & 0,09 & $\overline{55}$ & 0,8 & 0,1 & 0,01 & 0,1 & - & $=$ & - & 0,98 \\
\hline $\begin{array}{l}\text { MA-59B } \\
\text { MA-65 }\end{array}$ & $\begin{array}{l}11,18 \\
31,35\end{array}$ & 30,55 & 31,64 & 12,38 & $\overline{7}$ & 5,82 & 0,55 & 3,80 & 0,98 & 0,04 & 2,30 & - & $0<?$ & - & 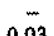 \\
\hline MA.65 & 31,35 & 31,34 & 34,25 & 0,17 & 0,70 & $m$ & - & 0,68 & 0,12 & - & 0,12 & + & 0,52 & - & 0,03 \\
\hline $\begin{array}{l}\text { CV-06A - Granito hololew } \\
\text { CV-66B - Granito gráfico } \\
\text { CV-18A - Mtcrograntito } \\
\text { CV-18B - Quartzo monzo } \\
\text { CV-18C - Granodionto } \\
\text { CV-18F - Granito gráfico } \\
\text { CV-20D - Mlcrogranito }\end{array}$ & & $\begin{array}{l}\text { cV-2 } \\
\text { cV-2 } \\
\text { cV-2 } \\
\text { cV.4 } \\
\text { cV.4 } \\
\text { cV-s } \\
\text { cV.5 }\end{array}$ & - Mic & Degme & & $\mathrm{Cl}$ & ${ }_{9 \mathrm{~A}}^{9 \mathrm{~N}-}$ & $\begin{array}{l}\text { ito } \\
\text { ito } R\end{array}$ & $\begin{array}{l}\text { de } \\
\text { itico } \\
\text { ico }\end{array}$ & & & & $\begin{array}{l}\text { ito ho } \\
\text { firo } \\
\text { oleuc } \\
\text { firo } \\
\text { blend } \\
\text { ito }\end{array}$ & sático & \\
\hline
\end{tabular}


fletem provavelmente os termos mais diferenciados do Granito Mandacaru.

Os elementos-traços $\mathrm{Ba}, \mathrm{Sr}, \mathrm{Rb}$ e $\mathrm{Cu}$ apresentam as maiores variaçðes nas rochas do Granito Mandacaru: $B a$ varia de 130 a $1.840 \mathrm{ppm}$, com valor médio de $1.164 \mathrm{ppm}$, valor este superior ao proposto por Turekian \& Wedepohl (1961, apud Vorma 1976) para as rochas graníticas de baixo e alto teor de $\mathrm{CaO}$, que é da ordem de 840 a $420 \mathrm{ppm}$, respectivamente; $\mathrm{Sr}$ varia de 18 a $855 \mathrm{ppm}$, com teor médio de $340 \mathrm{ppm}$; e Rb, com teor médio de $263 \mathrm{ppm}$, varia entre 188 e $570 \mathrm{ppm}$. Sr e Ba mostram uma diminuição em direção às rochas mais ácidas, caracterizadas pelos granitos hololeucocráticos e pelas rochas de diques e apófises granofíricas, granitos gráficos e microgranitos, enquanto $\mathrm{O} \mathbf{R b}$

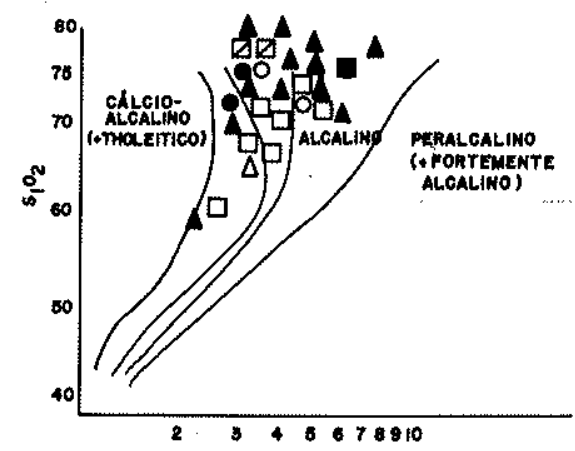

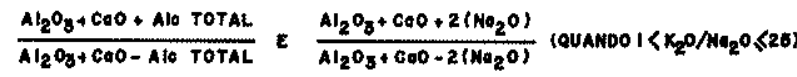

Figura 2 - Diagrama de variação do indice de alcalinidade (Wright 1969) para as rochas do Granito Mandacaru: fácies granito hololeucocrático $\square$; fácies granodiorito $\square$; fácies pegmatitico o; fácies rapakivi •; fácies granófiro pórfiron; e diques e apófises $\mathbf{A}$

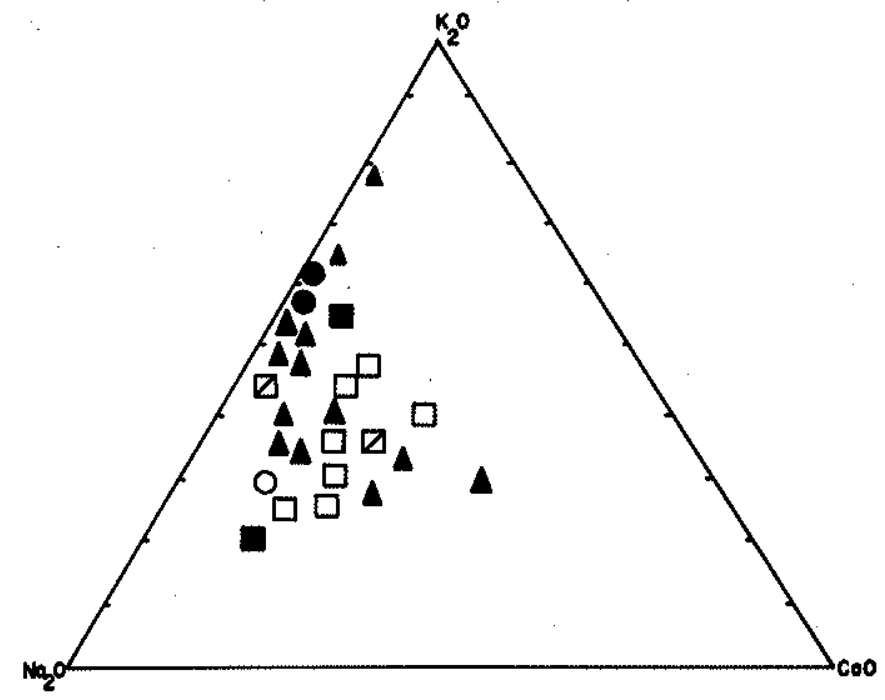

Figura 3 - Diagrama de variação $\mathrm{K}_{2} \mathrm{O}-\mathrm{CaO}-\mathrm{Na}_{2} \mathrm{O}$ do $\mathrm{Gra}$ nito Mandacaru apresenta enriquecimento. $\mathrm{O} \mathrm{Cu}$, com valores dominantemente entre 4 e $12 \mathrm{ppm}$, mostra três resultados anômalos de $400,5.600$ e $6.160 \mathrm{ppm}$, que correspondem a amostras colhidas nas zonas de borda do Granito Mandacaru e em apofises granofíricas intrudidas na Formação Catolé (Fig. 3). Este fato indica uma provável remobilização do $\mathrm{Cu}$ das rochas vulcânicas e sedimentares da Formação Catolé, durante a intrusão granítica. Os demais valores encontrados (4-12 ppm) são inferiores aos obtidos em granitos normais, que têm um teor médio em torno de 20 ppm (Taylor 1965) e, sobretudo, aos granitos do tipo $\mathrm{Cu}$-pórfiro, que apresentam um teor mínimo da ordem de 120 ppm (Mason \& MacDonald 1978).

Os demais elementos-traços - como F, Sn, Nb, Y, Mo, ' $\mathrm{Be}, \mathrm{Ga}, \mathrm{Li}$ e $\mathrm{Zr}$ - apresentam valores semelhantes aos propostos por Taylor (1965) para granitos normais (Tab. 2).

Tabela 2 - Quadro comparativo dos elementos-traços (ppm) do Granito Mandacaru com os elementos-traços dos granitos de Turekian \& Wedepohl (1961) (apud Vorma 1976) e Taylor (1963)

\begin{tabular}{|c|c|c|c|}
\hline \multirow{2}{*}{$\begin{array}{c}\text { Média do } \\
\text { Granito Mandacaru }\end{array}$} & \multicolumn{2}{|c|}{$\begin{array}{c}\text { Média dos granitos de } \\
\text { Turekian \& } \\
\text { Wedepohl (1961) }\end{array}$} & \multirow{2}{*}{$\begin{array}{l}\text { Média dos } \\
\text { granitos de } \\
\text { Taylor } \\
\text { (1965) }\end{array}$} \\
\hline & $\begin{array}{l}\text { Granito rico } \\
\text { em cálcio } \\
\end{array}$ & $\begin{array}{l}\text { Granito pobre } \\
\text { em cálcio }\end{array}$ & \\
\hline & $(\mathrm{CaO}>3 \%)$ & $(\mathrm{CaO}<1 \%)$ & \\
\hline $\begin{array}{r}230 \\
5 \\
20 \\
11 \\
5 \\
7 * \\
7 * \\
3,5 \\
1,8 \\
<50 \\
112 \\
263 \\
340 \\
1.164\end{array}$ & $\begin{array}{c}520 \\
- \\
- \\
- \\
- \\
- \\
- \\
- \\
24 \\
140 \\
110 \\
440 \\
420\end{array}$ & $\begin{array}{c}850 \\
= \\
= \\
= \\
= \\
= \\
\overline{40} \\
175 \\
170 \\
100 \\
840\end{array}$ & $\begin{array}{r}- \\
3 \\
20 \\
35 \\
2 \\
20 \\
3 \\
18 \\
27 \\
160 \\
120 \\
350 \\
550\end{array}$ \\
\hline
\end{tabular}

GEOCRONOLOGIA Foram realizadas inicialmente 14 determinações radiométricas pelo método $\mathrm{Rb}-\mathrm{Sr}$ em rochas do Granito Mandacaru (Parente 1984) e, em seguida, mais cinco análises pelo mesmo método, totalizando 19 amostras analisadas. Aliás, os novos dados apenas confirmaram os resultados obtidos por Parente (1984). As análises foram realizadas no laboratório de Geologia Isotópica da Universidade Federal do Pará. Os pontos de coleta das amostras são mostrados na figura 4 e os dados analíticos constam da tabela 3 .

A figura 5 représenta a isócrona de referência obtida para amostra de diques granofíricos. A isócrona, baseada em seis pontos, indica idade de $574 \pm 24 \mathrm{Ma}(2 \sigma)$ e razão inicial $\mathrm{Sr}^{87} / \mathrm{Sr}^{86}=0,7072 \pm 0,0043(2 \sigma)$, compativeis com os resultados apresentados em Parente (1984) (571 $\pm 26 \mathrm{Ma}$ e $\mathrm{Ri}=0,70914 \pm 0,00022)$. A qualidade do alinhamento dos pontos também é boa $(\mathrm{MSWD}=2,18$ ). Por outro lado, a inclusão de duas amostras de apófises granofíricas nesse conjunto de rochas (Fig. 6) dá uma idade de $556 \pm 10 \mathrm{Ma}$ $(2 \sigma)$ e $R I=0,7105 \pm 0,0005(2 \sigma)$, ambos de menores desvios 


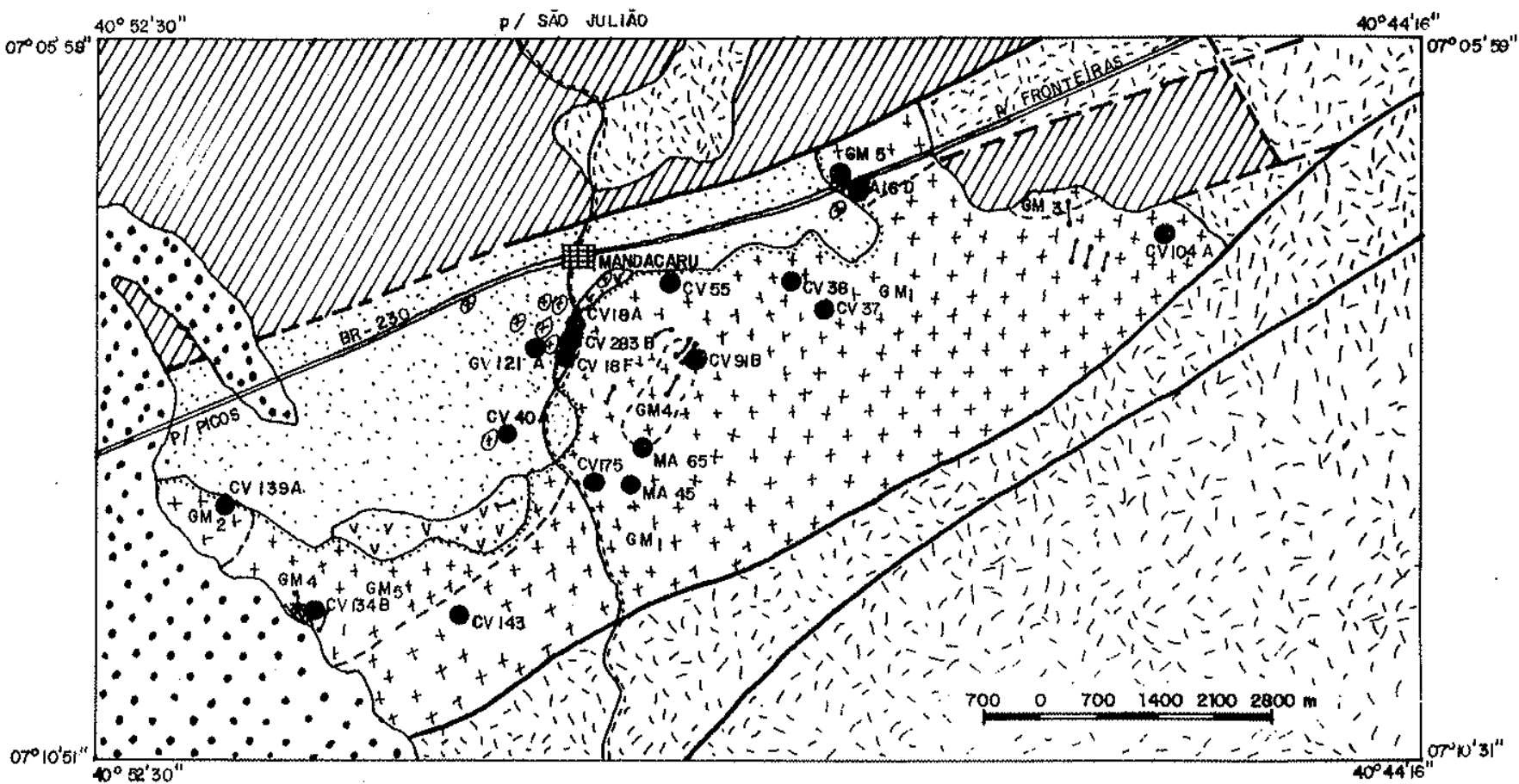

LEGENDA

OOOO FORMAGÃO SERRA GRANDE

VVV "PPES" DE GRECHA

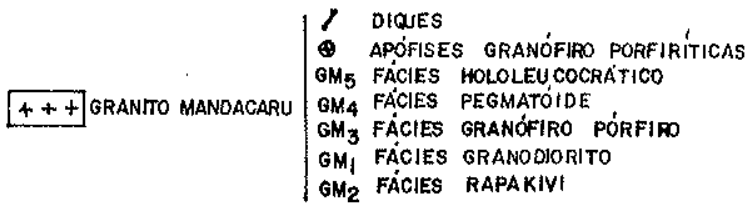

$\because$ T FORMACAOA CATOLE

DIIIII SEOU'ÉNCIA SÃo JULIĀO

Xiti: EMaAaAmENTO CRISTALINO
ALTERAÇÄO SECUNDÁRIA

EI PROPILITIZACÁO

(क) FILICA E/OU SERICITICA

ABGILIZACEĀO

SERITIZACĀO, ARGILIZACÃO E CLORITIZAGAOO

- amoothas con exconomoloeia

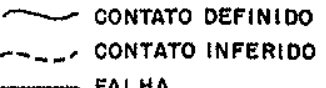

Figura 4 - Localização das amostras com geocronologia

Tabela 3 - Resultados radiométricos $R b-S r$ das rochas do Granito Mandacaru

\begin{tabular}{|c|c|c|c|c|c|c|}
\hline AMOSTRA & & LITOTIPO & $\mathbf{R b}(\mathbf{p p m})$ & Sr (ppm) & $\mathrm{Rb}^{87} / \mathrm{Sr}^{86}$ & $\mathrm{Sr}^{87} / \mathrm{Sr}^{86}$ \\
\hline $\begin{array}{l}\text { CV-134B } \\
\text { CV-37 } \\
\text { CV-283B } \\
\text { CV-213C } \\
\text { MA-16D } \\
\text { CV-139A } \\
\text { CV-104A } \\
\text { CV-18A } \\
\text { CV-18F } \\
\text { CV-175 } \\
\text { CV-143A } \\
\text { CV-38 }\end{array}$ & $\begin{array}{l}0 \\
8 \\
8 \\
8 \\
8\end{array}$ & $\begin{array}{l}\text { Hornblenda-quartzo monzonito } \\
\text { Granodiorito } \\
\text { Granodiorito } \\
\text { Granito hololeucocrático } \\
\text { Granito hololeucocrático } \\
\text { Granito Rapakivi } \\
\text { Granito leucocrático } \\
\text { Microgranito } \\
\text { Granito gráfico } \\
\text { Quartzo pórfiro } \\
\text { Quartzo pórfiro } \\
\text { Quartzo pórfiro }\end{array}$ & $\begin{array}{l}144,4 \pm 3,3 \\
144,7 \pm 3,3 \\
153,5 \pm 3,6 \\
123,1 \pm 2,8 \\
192,0 \pm 13,0 \\
198,7 \pm 4,9 \\
123,3 \pm 2,7 \\
187,1 \pm 4,0 \\
363,3 \pm 9,1 \\
230,7 \pm 5,3 \\
215,1 \pm 4,9 \\
216,4 \pm 5,0\end{array}$ & $\begin{array}{r}1.101,0 \pm 12,0 \\
545,2 \pm 5,7 \\
266,6 \pm 3,1 \\
79,96 \pm 0,88 \\
53,80 \pm 13,40 \\
53,9 \pm 1,10 \\
466,8 \pm 4,70 \\
78,47 \pm 0,76 \\
48,89 \pm 0,50 \\
38,83 \pm 0,39 \\
55,20 \pm 0,55 \\
71,90 \pm 0,74\end{array}$ & $\begin{array}{r}0,3796 \pm 0,0040 \\
0,7843 \pm 0,0077 \\
1,6710 \pm 0,0200 \\
4,4920 \pm 0,0430 \\
10,4900 \pm 0,1200 \\
6,2010 \pm 0,0850 \\
0,7645 \pm 0,0065 \\
6,9760 \pm 0,650 \\
22,5000 \pm 0,3500 \\
17,4300 \pm 0,2000 \\
11,3800 \pm 0,1300 \\
8,7700 \pm 0,1000\end{array}$ & $\begin{array}{l}0,712239 \pm 0,000025 \\
0,715602 \pm 0,000046 \\
0,733727 \pm 0,000034 \\
0,797872 \pm 0,000065 \\
0,869906 \pm 0,000027 \\
0,833567 \pm 0,000034 \\
0,715325 \pm 0,000035 \\
0,820590 \pm 0,000160 \\
1,183530 \pm 0,000026 \\
0,849852 \pm 0,000085 \\
0,799195 \pm 0,000091 \\
0,778073 \pm 0,000034\end{array}$ \\
\hline $\begin{array}{l}\text { CV-40A } \\
\text { MA-45 } \\
\text { CV-121A } \\
\text { CV }-55 \\
\text { CV-91B } \\
\text { MA-65 }\end{array}$ & 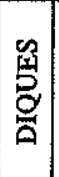 & $\begin{array}{l}\text { Granófiro porfíritico } \\
\text { Granófiro } \\
\text { Granófiro porfirítico } \\
\text { Microgranito } \\
\text { Quartzo pórfiro } \\
\text { Granofiro }\end{array}$ & $\begin{array}{l}148,4 \pm 3,5 \\
234,4 \pm 5,4 \\
163,8 \\
152,50 \\
210,40 \\
237,70\end{array}$ & $\begin{array}{cc}239,50 \pm & 2,80 \\
22,20 \pm & 0,22 \\
387,1 & \\
82,08 \\
58,82 \\
51,90\end{array}$ & $\begin{array}{r}1,7960 \pm 0,0210 \\
31,3000 \pm 0,3700 \\
1,226 \pm 0,011 \\
5,422 \pm 0,055 \\
10,430 \pm 0,110 \\
13,400 \pm 0,160\end{array}$ & $\begin{array}{l}0,724741 \pm 0,000049 \\
0,960053 \pm 0,000095 \\
0,720380 \pm 0,000190 \\
0,792400 \pm 0,001600 \\
0,793360 \pm 0,000190 \\
0,819630 \pm 0,000068\end{array}$ \\
\hline
\end{tabular}


que os dados anteriores e de perfeita compatibilidade (superposição de valores levando-se em conta os desvios), o que indica que eles são perfeitamente relacionados.

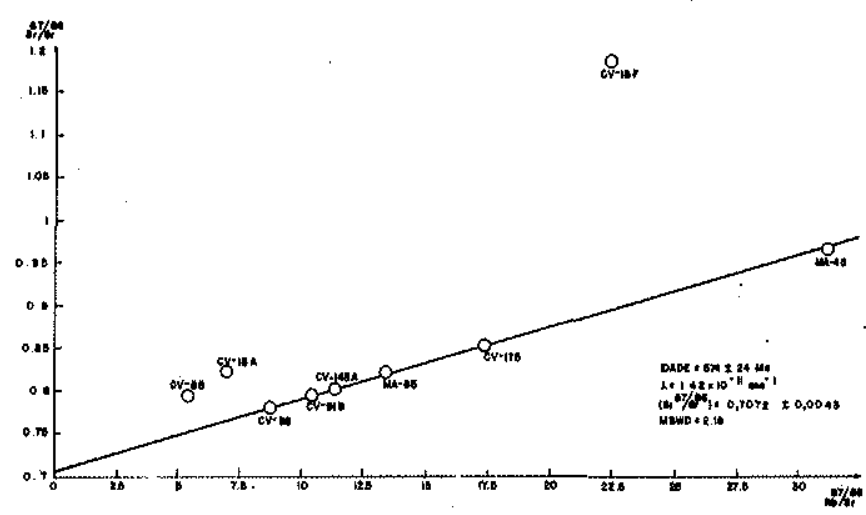

Figura 5 - Isócrona Rb-Sr de referência em rocha total de diques granofiricos do Granito Mandacaru

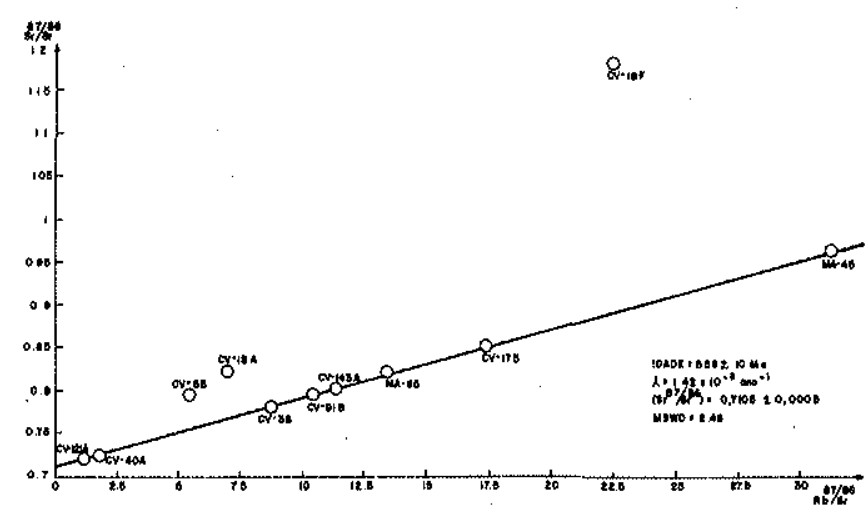

Figura 6 - Isócrona de referência em rocha total de diques do Granito Mandacaru

As três amostras representadas por microgranitos e granito gráfico, que fogem da isócrona, podem ser interpretadas geocronologicamente de várias maneiras: 1) contemporâneas dos granófiros: (1a) com razão inicial mais alta; (1b) com a mesma razão inicial, porém com contaminaçðes (contemporânea ou posterior) por Sr radiogênico; (1 c) com a mesma razão inicial, porém apresentando perda recente de $\mathrm{Rb}$; 2) e mais antigas: (2a) sem notável perturbação isotópica e nem químicas; e (2b) com perturbação contemporânea ou posterior. A hipótese (1c) não pode ser aceita, pelo menos isoladamente, por implicar perda de cerca de $50 \%$ de $\mathrm{Rb}$ no caso dos microgranitos e ainda mais em relação ao granito gráfico. As hipóteses (2a) e (2b) são descartadas pelos dados de campo e petroquímicos, uma vez que tanto os microgranitos como o granito gráfico correspondem às rochas mais diferenciadsa da intrusão granítica. A hipótese (1a) é aceitável, a rigor, para os microgranitos $(R I=0,8)$ mas não seria recomendável para o granito gráfico $(R I=1)$. Neste caso,as hipóteses (la) e (1b) seriam mais prováveis considerando o grau de diferenciação das rochas analisadas, bem como o fato de terem sido coletadas na borda da intrusão granitica, junto do contato com a Formação Catolé (Fig. 4), podendo ter sido contaminadas por $\mathrm{Sr}^{87}$ radiogênico das encaixantes.

$\mathrm{Na}$ figura 7 está representada a iścrona de referência obtida para as rochas plutônicas. $\mathrm{A}$ isócrona indica idade de $571 \pm 26 \mathrm{Ma}$, com razão inicial de $0,70914 \pm 0,00022$. Ape sar de construída com apenas três pontos analíticos, a isócrona é confiável em face dos resultados obtidos para os diques granofíricos. Existe também a compatibilidade das duas razões iniciais, dentro do erro analítico, as das rochas plutônicas sendo conhecidas com mais precisão uma vez que essas rochas exibem baixa razão $\mathrm{Rb} / \mathrm{Sr}$, os pontos representativos situando-se próximos à origem dos eixos.

A utilização conjunta dos dados de rochas plutônicas e dos diques resulta em uma isócrona de boa qualidade para o granito como um todo, alinhando cinco amostras de granófíros e três de granitóides. A idade obtida é de $559 \pm 8 \mathrm{Ma}$ e razão inicial de $0,70924 \pm 0,00010$ (Fig. 9). 0 fato de estes diferentes tipos litológicos apresentarem a mesma idade e razão inicial aproximadamente similar, aliado ao bom alinhamento das amostras, como é confirmado pelo baixo valor do parâmetro $\operatorname{MSDW}(1,11)$, permite a confirmação implícita de que os diques (ou pelo menos parte deles) e as rochas plutônicas do Granito Mandacaru podem ser considerados contemporâneos ou co-genéticos, o que vem confirmar os dados de campo e os estudos petroquímicos. Nesse sentido, as rochas dos diques devem representar produtos mais diferenciados das rochas plutônicas, o que justifica a razão inicial mais alta. No diagrama isocrônico em referência, podem-se verificar também várias amostras de rochas granitóides plotadas fora da isócrona e em posição bem acima dela. Assim como foi o caso com os diques de microgranitos e granito gráfico, a disposição caótica dessas amostras permite inferir basicamente duas hipóteses: 1) contemporâneas, mas com contaminação ou 2) mais antigas, com perturbação isotópica ou não. Da mesma maneira que os diques acima referidos, todas essas rochas granitóides provêm da zona de contato da intrusão granítica com a Formação Catolé, em oposição às oito amostras da isócrona que procedem de partes mais internas do Granito Mandacaru. Como se discutiu em Parente (1984) e Parente \& Fuck (no prelo), o Granito Mandacaru experimentou, durante os estágios finais de cristalização, interação com água meteó. rica e das encaixantes, fato este que modificou o sistema $\mathrm{Rb}-\mathrm{Sr}$, como indica a dispersão dos pontos da figura 8 . Desse modo, as importantes modificações no contingente do $\mathrm{Sr}^{87}$ radiogênico (incorporação) ou de $\mathrm{Rb}$ (perda) foram impostas por fluidos aparentemente provenientes das encaixantes que circularam no Granito Mandacaru, sobretudo nas zonas de contato e nas rochas em que se verificou maior cataclase. Trata-se provavelmente dos mesmos fluidos que alteraram e modificấram a associação mineral original das rochas graníticas.

\section{ALGUNS COMENTARIOS QUANTO A ORIGEM DO} GRANITO MANDACARU Considerando a escassez de fluidos magmáticos representados pelos baixos teores de $\mathrm{H}_{2} \mathrm{O}, \mathrm{F}, \mathrm{Sn}, \mathrm{Nb}$, Mo e $\mathrm{Li}$, que são elementos comumente encontrados em fase de hidrotermalismo, e as feições de alteraçōes discutidas (Parente \& Fuck no prelo), acredita-se que o agente responsável pela alteração do Granito Mandacaru foi água meteórica ou água oriunda das encaixantes, associadas possivelmente a fluidos liberados durante a rápi- 
da cristalização dos diques pórfiros, o que poderia ser confirmado com um estudo isotópico de oxigênio e hidrogênio.

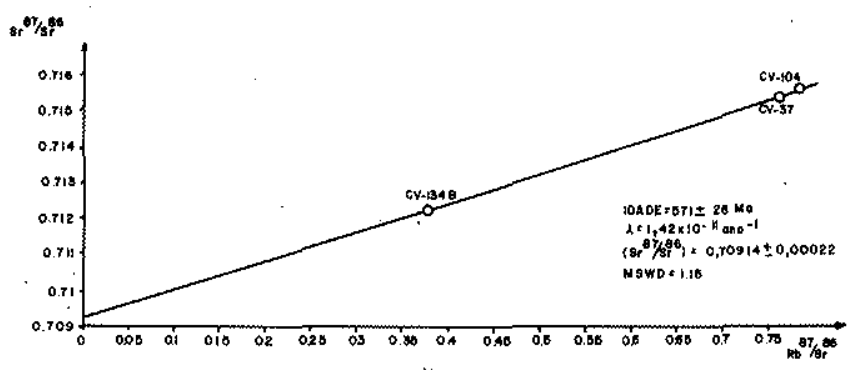

Figura 7 - Isócrona de referência em rocha total de rochas plutônicas do Granito Mandacaru

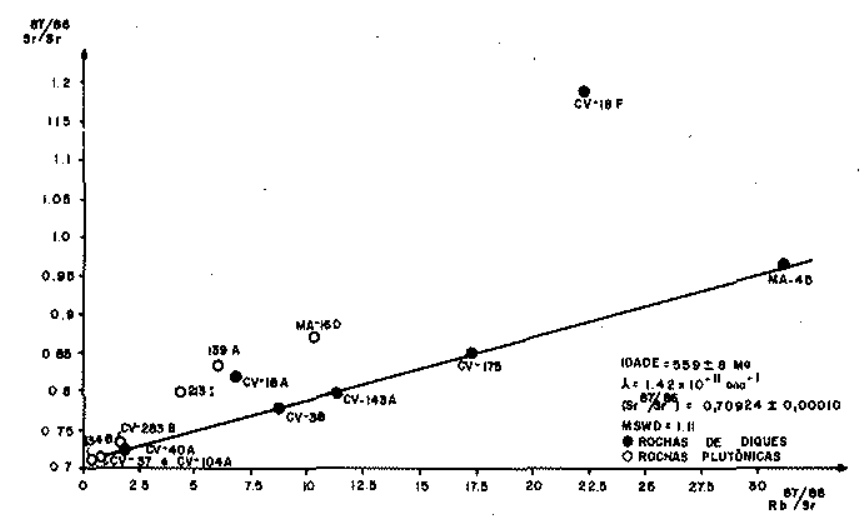

Figura 8 - Isócrona de referência em rocha total do Granito Mandacaru

A razão inicial $\mathrm{Sr}^{87} / \mathrm{Sr}^{86}$ do Granito Mandacaru, inferior a 0,710 , porém superior às razões iniciais de magmas derivados do manto $(0,706)$, permite inferir várias possibilidades para a derivação do magma original. Pode tratar-se 1) de material derivado por fusão da crosta inferior (granulítica) empobrecida em $\mathrm{Rb} / \mathrm{Sr}$; 2) de magma derivado do manto superior e contaminado por assimilação parcial de material da crosta inferior; 3) de material siálico que tenha tido um curto tempo de permanência na crosta; ou 4) de material derivado por fusão parcial de rochas contendo apreciável contribuição de vulcânicas, conforme assinalado por Cordani (apud Dantas 1974), para rochas graníticas da Faixa de Dobramentos Jaguaribeana.

As feições petrográficas e geoquímicas do Granito Mandacaru, no entanto, indicam que a fonte mais provável é de magma derivado do manto superior, que sofreu contaminação por parte da crosta inferior, seca e geoquimicamente estéril (crosta granulítica).

A julgar pelas feições supracitadas e o emplacement dessas rochas em ambiente geológico distensional intracratônico, pode-se dizer, também, que o Granito Mandacaru corresponde aos granitos tipo A (Loiselle \& Wones 1979, Collins et al. 1982, Pitcher 1983).
O magma granítico assim formado ascendeu ao longo da estrutura tipo gráben; e dado o baixo teor de $\mathrm{H}_{2} \mathrm{O}$, pode migrar quase até a superfície sem cruzar o solidus. Ao posicionar-se, formou-se margem resfriada representada pelo fácies granofírico e microgranítico devido ao próprio contraste térmico com as rochas encaixantes.

Subseqüentes acomodações tectônicas reativaram falhas e fraturas, e rompeu-se a carapaça previamente formada, o que permitiu a injeção do material do centro do plutão ao longo das fraturas, principalmente nas marginais e naquelas que cortam as rochas sedimentares da Formação Catolé. $O$ caráter profirítico dos diques no interior e nas bordas do corpo bem como das apófises com matriz granofírica introduzidas nas rochas sedimentares, além do fácies de granulação fina, são atestado adicional do caráter intrusivo dessas rochas ao longo de fraturas neoformadas. Devido à baixa pressão confinante, desenvolveram-se ainda, ao longo de fraturas marginais, pequenos veios pegmatíticos e de granito gráfico, apesar da limitada concentração de voláteis. Por outro lado, o remanescente magma cristalizou lentamente, e produziu as texturas pegmatíticas.

O caráter anidro das rochas plutônicas, a escassez de veios pegmatíticos, a associação com riólitos e granófiros, e a presença de rochas máficas efusivo-fissurais constituem feições geológicas que suportam esta interpretação.

As características petrográficas, litoquímicas e o ambiente tectônico do Granito Mandacaru permitem também descaracterizá-lo como granito tipo Cu-pórfiro, visto que a formação de depósitos deste tipo exige condições bastantes especiais e diferentes das que ocorrem nas rochas graníticas intrusivas de Mandacaru. Os depósitos tipo $\mathrm{Cu}$-pórfiro encontram-se, em geral, associados ao magmatismo cálcioalcalino; cristalizam-se em condições de alta $\mathrm{PH}_{2} \mathrm{O}>2 \%$ $\mathrm{H}_{2} \mathrm{O}$ ); as instrusões mineralizadas no estilo de $\mathrm{Cu}$-pórfiro mostram pouca diferenciação, quartzo diorito, quartzo monzonito e granodiorito sendo os termos petrográficos mais freqüentes; o ambiente tectônico dessas rochas está relacionado a regióes de convergência de placas; e as alterações hidrotermais são zonadas, a elas se superpondo a mineralização, bem ao contrário do que apresenta o Granito Mandacaru.

Considerando a idade geocronológica $559 \pm 6 \mathrm{Ma}(20)$ bem como as características petrográficas e petroquímicas do Granito Mandacaru e suas relações com as rochas encaixantes, pode-se equipará-lo aos granitos Mucambo e Meruoca do NW do Ceará. Para esses granitos, Sial et al. (1981) reportam idades de $548 \pm 24 \mathrm{Ma}(\mathrm{RI}=0,710 \pm 0,0011) \mathrm{e}$ $507 \pm 36 \mathrm{Ma}(\mathrm{RI}=0,7071 \pm 0,0015)$, respectivamente. De acordo com esses autores, a idade menor e a razão inicial mais baixa do Granito Meruoca representam modificações no sistema $\mathrm{Rb} \cdot{ }_{-} \mathrm{Sr}$ imposta por alterações meteóricas, o que mascara sua verdadeira identidade geocronológica, que, para aqueles autores, seria equivalente à do Granito Mucambo, isto é, aproximadamente $550 \mathrm{Ma}$. Os três corpos estão relacionados ao mesmo evento magmático, que caracteriza a fase pós-tectônica do Ciclo Brasiliano na Região de Dobramentos Nordeste.

CONCLUSÃo O Granito Mandacaru representa uma intrusão pós-tectônica, gerada em ambiente geológico distensional intracratônico. Encontra-se introduzido na Formação Catolé, na seqüêencia São Julião e nas rochas granito. gnáissicas mais antigas. Os estudos petrográficos, petroquímicos e geocronológicos indicam que o Granito Mandacaru representa um plutão diferenciado, formado a partir 
de magma subalcalino a alcalino, pobre em $\mathrm{H}_{2} \mathrm{O}$, proveniente da crosta inferior, e resultante da interação de material juvenil com esta crosta, que provavelmente seria seca e geoquimicamente estéril (crosta granulítica). 0 magma granítico assim formado ascendeu ao longo da estrutura tipo gráben $\mathrm{e}$, dado $\mathrm{o}$ baixo teor de $\mathrm{H}_{2} \mathrm{O}$, pode migrar quase à superfície sem cruzar o solidus. As características supracitadas permitem dizer também que o Granito Mandacaru corresponde aos granitos tipo A. Posicionado a $550 \mathrm{Ma}$, o Granito Mandacaru apresenta estreita relação com os granitos pós-tectônicos Meruoca e Mucambo do noroeste do Ceará, apesar de, nestes dois últimos, não se ter conhecimento da presença de mineralização de cobre.

Agradecimentos Os autores agradecem ao $\mathrm{CNPq}$, pelo suporte financeiro (Proc. 40.3563/81); a Geraldo Resende Boaventura, do Laboratório de Geoquímica da UnB, pela realização de parte das análises químicas; e aos professores do Departamento de Geociências da $\mathrm{UnB}$, em particular Marcel A. Dardenne e Hardy Jost, pela ajuda nos trabalhos de laboratório.

\section{REFERENCIAS BIBLIOGRAFICAS}

CLARKE, D.B. - 1981 - The mineralogy of peraluminous granites: A review. Canadian Mineralogist, 19:3-17.

COLLINS, W.J.; BEAMS, S.D.; WHITE, A.G.R.; CHAPPELL, B.W. - 1982 - Nature and origin of A-type Granites with particular reference to southeastern Australia. Contr. Min. Petrol., 80:189-200.

DANTAS, J.R.A. - 1974 - Carta Geologica do Brasil ao Milionésimo. Folha Jaguaribe (SB-24) e Folha Fortaleza (SA-24), Brasil. Brasília, DNPM, $95 \mathrm{p}$.

FARINA, M. - 1980 - Mineralizaçấo cupro-argento aurifera de São Juliâo, Piaul. Caracterização Geológica preliminár do primeiro "Porphyry Copper" do Brasil. Recife, CPRM, 19 p. (inédito)

GÄAL, E.G. - 1982 - Evaluation of the copper prospect of Mandacaru-PI, with impressions on the Geology of Noroeste and Rio Capim field trip. Salvador, Caraíba Metais S.A. 3p. (inédito).

HANSON, G.N. - 1978 - The application of trace elements to the petrogenesis of igneous rocks of granitic composition. Earth and Planetary Science Letters, 38:26-43.

LOISELLE, M.C. \& WONES, D.R. - 1979 - Characteristics of anorogenic granites. Abstr. with programs Geol. Soc. Am. A. G.M.; 539 .

LOPES FILHO, J.B.; LAGES, P.R.R.; SILVA, R.O.C.; NETO, M.C.; URBANO FILHO, C. - 1982 - Projeto Cobre-Mandacaru. COMDEPI/PI. (inédito).

MASON, D.R. \& MacDONALD, J.A. - 1978 - Intrusive rocks and porphyry copper occurences of Papua New Guinea-Solomon Islands Region: A reconnaissance Study. Econ. Geol, 73:857-877.

NEVES, B.B. de B. - 1975 - Regionalização geotectônica do Precambriano nordestino, Sáo Paulo, $198 \mathrm{p}$. (Tese de Doutoramento, Institu to de Geociências da USP).

NEVES, B.B. de B - 1978 - A Propósito da evolução lito-estratigrá fica do Precambriano Superior do Nordeste. Jom. Miner, 7:19-27, Recife.

NEVES, B.B. de B. - 1983 - O mapa geológico do Nordeste oriental do Brasil.: Escala 1:1.000.000. São Paulo, (Tese de Livre-Docência, Instituto de Geociências da USP).
PARENTE, C.V. - 1984 - Geologia da mineralização de cobre de Mandacaru-PI. Brasília, 203 p. (Tese de Mestrado, Departamento de Geociências da UnB).

PARENTE, C.V. \& FUCK, R.A. - 1986 - Geologia da ocorrència de cobre de Mandacaru, Piauí. Rev. Bras. Geoc, (no prelo).

PITCHER, W.S. - 1983 - Granite type and tectonic environment. In: HSU, K. (ed.). Mountain Building Processes. Academic Press, London, p. 19.40.

SIAL, A.N.; FIGUEIREDO, M.C.H; LONG, L.E. - 1981 - Rare earth element geochemistry of the Meruoca and Mucambo plutons, Ceará, northeast Brazil: Chemical Geology, $31: 271-283$.

TAYLOR, R.R. - 1965 - The application of trace element data to problems in petrology. Physics and Chemistry of the Earth, 6:133-213.

TERAZU, Y. - 1980 - Relatório sobre a mineralização de cobre de São Juliāo-Piaut. Cooperação Técnica Brasil-Japão. DNPM/: DGM. (inédito).

TERAZU, Y. - 1981 - Relatório sobre a mineralização de cobre de São Julião (II). Cooperação Técnica Brasil-Japão. DNPM/DGM. (inédito).

TUREKIAN, K.K. \& WEDEPOHL, W.H. - 1961 - Distribution of elements of some major units of Earth's crust. Geol. Soc. Am. Bull. 72:175-192.

TURNER, J.T. - 1981 - Metamorphic petrology. Ed. Hemisphere Publishing Corporation. $524 \mathrm{p}$.

TUTTLE, O.F. \& BOWEN, M.L. - 1958 - Origin of granite in the light of experimental studies in the system $\mathrm{NaAlSi}_{3} \mathrm{O}_{8}$. KAlSi $\mathrm{O}_{8}-\mathrm{SiO}_{2} \mathrm{H}_{2}$ O. Geol. Soc. Am. Memoir, 74:153 p.

VORMA, A. - 1976 - On the petrochemistry of Rapakivi Granites with special reference to the Laitila massif, sothwestern Fin" land. Geol Surv. Finl. Bull., 285:1-98.

WRIGHT, J.B. - 1969 - A simple alkalinity ratio and its application to questions of non-orogenic granite genesis. Geol. Mag., 106(4):370-384.
MANUSCRITO

Recebido em 23 de maio de 1986 Revisão aceita em 18 de novembro de 1986 